\title{
Input variability and late acquisition: Clitic misplacement in European Portuguese
}

\author{
João Costa *, Alexandra Fiéis, Maria Lobo \\ FCSH-Universidade Nova de Lisboa/CLUNL, Av. de Berna, 26C, 1069-061 Lisboa, Portugal
}

Received 1 April 2013; received in revised form 24 March 2014; accepted 18 May 2014

\begin{abstract}
This paper reports a study on the acquisition of clitic placement by European Portuguese children aged 5, 6 and 7, using an elicitation task. Contrarily to what has been found for other languages, where children correctly place clitic pronouns from a very early age, our results show that European Portuguese children still misplace clitics at age 7, although there is a developmental effect from 5 to 7 : they overuse enclisis in proclisis contexts, but not the other way round. This confirms previous studies based on spontaneous production. Our study shows, however, that: i) the rates of clitic misplacement are not identical in all proclisis contexts; ii) proclisis is acquired earlier in some contexts; iii) the contexts that are harder to acquire are the ones where we find more variability in the adult control group, and where diachronic data are not so categorical. We argue that, since clitic placement in European Portuguese is not linked to the finite/non finite distinction, there is a slower developmental path, reflecting the complexity of the input and the specific properties of lexical items and syntactic contexts.
\end{abstract}

(C) 2014 Published by Elsevier B.V.

Keywords: Clitic placement; European Portuguese; Acquisition; Variable input

\section{Introduction}

Crosslinguistic acquisition studies show that word order phenomena are usually acquired very early: children's first productions are consistent with the head directionality of their target language and with verb placement related to finiteness and with verb movement.

Studies on the acquisition of clitics show that, although there may be clitic omission in initial stages of language acquisition, in most languages clitics are placed in a target-like manner (see Guasti, 1993/94; Wexler et al., 2004; Hamann et al., 1996; Grüter, 2006; Marinis, 2000; among others). In Italian, Spanish, Catalan, French and Standard Greek, children produce clitics in preverbal or postverbal position, according to the system they are acquiring.

In European Portuguese (EP) and in Cypriot Greek, however, children seem to display deviant patterns of clitic placement (see Duarte et al., 1995; Petinou and Terzi, 2002; Neokleous, in press). These two languages differ from other languages in that the patterns of clitic placement are not linked to finiteness.

Although clitic misplacement has been described for EP based on spontaneous production data (see Duarte et al., 1995), there are no systematic studies on the acquisition of clitic placement in EP, which, at the same time, control for different syntactic contexts. Therefore, our study is designed to investigate the following questions:

\footnotetext{
* Corresponding author. Tel.: +351 7908300.

E-mail address: jcosta@fcsh.unl.pt (J. Costa).
} 
i) What are the patterns of clitic placement found in the acquisition of EP?

ii) Do children master enclitic contexts in the same way as proclitic contexts?

iii) Is clitic placement identical across different syntactic contexts?

iv) Can acquisition data contribute to the understanding of adult grammar?

Our paper is organized as follows. In section 2, we describe the patterns of clitic placement in contemporary EP, contrasting it with other languages and other Portuguese varieties. In section 3 , we report previous studies on the acquisition of clitics. In section 4, we describe the methodology and the results of an experiment designed to elicit clitics in different positions, and we show that clitic misplacement in EP is found until much later age than in other languages and that the rates of correct clitic placement are not identical across different contexts: clitic placement is acquired earlier in some contexts. In section 5, we discuss the results and propose that the development of clitic placement in EP is dependent on the complexity of each specific syntactic context and on lexical specification, which in turn induces input variability.

\section{Patterns of clitic placement}

In Romance languages, pronominal clitics are phonologically weak forms that obligatorily take a verb as their host. The clitic pronoun is always adjacent to a verb.

Contemporary Romance languages may roughly be organized in three groups, in what concerns clitic placement with respect to their host verb:

i) in type A languages, such as Italian or Spanish, clitic placement is linked to finiteness: enclisis is found in non finite clauses, whereas proclisis is found in finite clauses (cf. (1));

ii) in type B languages, such as French, clitics occur only in preverbal position (cf. (2)), no matter the inflectional status of the clause - finite or non finite ${ }^{1}$;

iii) in type $C$ languages, such as $E P,{ }^{2}$ there is variation in clitic placement, but it does not depend on finiteness - three patterns of clitic placement can be found in finite clauses: proclisis - the clitic precedes the verb (cf. (3a)); enclisis - the clitic follows the verb (cf. (3b)); and mesoclisis - the clitic occurs within the verb (cf. (3c)):

(1)
a. Gianni gli telefona.
Gianni CL-him calls
'Gianni calls him'
b. Gianni ha deciso di telefonargli.
Gianni has decided to call-CL-him
'Gianni has decided to call him'

(2) a. Jean lui téléphone.
Jean CL-him calls
'Jean calls him'

\footnotetext{
${ }^{1}$ In French, object pronouns only occur in post-verbal position in imperatives, where the pronoun may have a different form, bear stress and pronoun clusters may have a different order:

i) Donne-le-moi!

Give-it-me

'Give it to me'

ii) II me le donne.

$\mathrm{He}$ me it gives

'He gives it to me'

${ }^{2}$ Brazilian Portuguese (BP) is closer to French, displaying a dominant proclitic pattern, but differently from French it still exhibits enclisis. Modern BP also differs from Modern EP in disobeying the Tobler-Mussafia Law, that is BP allows first position clitics, (i) and admitting clitic adjacency to a past participle (ii):

i) Me beija me kiss 'Kiss me'

ii) Ela tinha certamente the falado She had certainly her spoken 'She had certainly spoken to her'
} 

b. Jean a décidé de lui téléphoner.
Jean has decided to CL-him call
'Jean has decided to call him'

(3) a. O João não Ihe telefonou.

the João not CL-him called

'João did not call him'

b. O João telefonou-Ihe.

the João called-CL-him

'João called him'

c. O João telefonar-lhe-á.

the João call-CL-him-FUT

'João will call him'

As described by several authors (see Duarte and Matos, 2000; among others), in EP proclisis is found in specific syntactic contexts ${ }^{3}$ : i) with negation (4); ii) with preverbal negative subjects (5); iii) with some preverbal adverbs, such as já 'already', ainda 'yet', sempre 'always/after all', também 'also', só 'only', among others (6); iv) with some quantified subjects in preverbal position (7)-(8); v) clauses with a filled CP, including wh-questions, wh-exclamatives (9); vi) subordinate finite clauses with an overt complementizer (10); vii) clauses with focus fronting (11):

(4) $O$ João não se lavou.

the João not CL3refl washed

'John did not wash himself'

(5) Ninguém se lavou.

nobody CL3refl washed

'Nobody washed himself'

(6) a. $O$ João já se lavou.

the João already CL3refl washed

b. O João lavou-se já.

the João washed-CL3refl already

'João has already washed himself'

(7) a. Todos os meninos se lavaram.

All the boys CL3refl washed

b. Lavaram-se todos os meninos.

Washed-CL3refl all the boys

'All the boys washed themselves'

(8) Dois meninos lavaram-se.

Two boys washed-CL3refl

'Two boys washed themselves'

(9) a. Quem se magoou?

Who CL3refl hurt

'Who hurt himself?'

b. Que bem lhe respondeste!

How well CL3dat answered

'You answered him so well!'

\footnotetext{
${ }^{3}$ Proclisis only occurs if the proclisis trigger c-commands the clitic and the verb.
} 

a. O João disse que se lavava todos os dias. the João said that CL3refl washed all the days 'João said that he washed himself every day'
b. $O$ João cheira bem porque se lava todos os dias. the João smells nice because CL3refl washes all the days 'João smells nice because he washes himself every day'

Muita água se perdeu!

Much water CL-3refl lost

'So much water was lost!'

Enclisis is found in the absence of proclisis triggers, in main clauses and in most coordinate clauses ${ }^{4}$ :

O João lavou-se.

the João washed-CL3refl

'João washed himself'

(13) A mãe abriu a torneira e o João lavou-se.

the mother opened the tap and the João washed-CL3refl

'His mother opened the tap and João washed himself'

Mesoclisis is only found with the simple future and with the conditional in the absence of proclisis triggers (14):
a. Lavar-me-ei.
Lavar-me-ia.
Wash-CL1sg-will Wash-CL1sg-would
'I will wash myself' 'I would wash myself'
b. Não me lavarei. Não me lavaria.
Not CL-1sg wash-will Not CL-1sg wash-would
'I will not wash myself' 'I would not wash myself'

When we consider infinitival clauses and verb clusters, the patterns are even more complex, since there is clitic climbing in EP and the clitic in some cases can either be adjacent to the non finite verb or to the finite one. We will not consider these patterns here. It is worth mentioning that clitic placement does not vary according to the type of clitic: all clitics behave the same with respect to clitic placement. ${ }^{5}$

Clitic placement is one of the most studied phenomena in Portuguese linguistics. Not only because the patterns of clitic placement are so special, but also because it is an interesting phenomenon in what concerns language change. As described by several authors there have been important changes in clitic placement diachronically and there is variation between different contemporary varieties of Portuguese.

In Old Portuguese, there is variation between enclisis and proclisis (in current enclitic contexts). However, in contexts where we have proclisis in Contemporary EP, we already had proclisis. Another property that distinguishes clitic placement in Old Portuguese is the fact that there was generalized interpolation, that is, the clitic might not occur adjacent to the verb (see Martins, 1994; Fiéis, 2001). In Classical Portuguese, patterns of clitic placement change:

\footnotetext{
${ }^{4}$ Some cases of correlative coordination, however, may induce proclisis:
}

(1) ?Das duas uma: ou as faz ela ou as faço eu.

Of the two one: or CL.ACC does she or CL.ACC do I

'One of two: either she does them or I do them.'

(Sttau Monteiro, apud Cunha \& Cintra 1984: 314)

${ }^{5}$ For some speakers, though, in clitic climbing contexts, the nature of the clitic may play a role as to the acceptability of the clause (cf. Fiéis and Madeira, 2012):

$\begin{array}{cccl}\text { (i) ?A } & \text { Maria pode-o } & \text { ver. } \\ \text { the } & \text { Mary wants-him } & \text { to_see. } \\ \text { (ii) } A & \text { Maria pode-te } & \text { ver. } \\ & \text { The Mary wants-you } & \text { to_see. }\end{array}$ 
proclisis becomes dominant and interpolation is much more restricted (Galves, 2003; Paixão de Sousa, 2004; Galves et al., 2005a,b). Enclisis, which is the modern pattern, becomes dominant in the 19th century (Paixão de Sousa, 2004).

In what concerns synchronic variation, we can also find differences across different national varieties of Portuguese. As described by several authors (Pagotto, 1996; Martins, 2011), in Brazilian Portuguese, proclisis is the dominant pattern, a past participle may host a clitic and we can find initial clitics, although there are still prescriptive grammar rules that condemn this useAs we can see, considering both diachronic and synchronic data, there are changes in the array of contexts where we can find enclisis, although proclitic contexts seem to be stable both diachronically and across the two varieties, except perhaps for some finite complement clauses.

Although clitic placement has been the subject of many studies, there is no consensus in what concerns the explanation for the proclisis-enclisis variation in EP. In fact, there are several theoretical proposals to account for clitic placement in EP, but, since it is not our goal to give a detailed description of these analyses here, we will only present their main assumptions, and state their implications for the acquisition data.

According to different authors, clitic placement in EP is triggered by: i) properties of the high peripheral functional domain (see Madeira, 1992; Martins, 1994; Rouveret, 1992; among others); ii) specific syntactic triggers (see Duarte and Matos, 2000); iii) syntactic and prosodic factors (see Frota and Vigário, 1996; Barbosa, 1996).

For some authors, proclisis is a less marked pattern and enclisis corresponds to a more complex derivation, where the $\mathrm{V}$ moves to a higher functional category (e.g. Martins, 1994); for others, enclisis is less complex and proclisis is a pattern computationally more costly, which is triggered by specific syntactic elements (see Duarte et al., 1995; Duarte and Matos, 2000).

According to Duarte et al. (2005), differences between languages in what concerns clitic placement are determined by a Proclisis Parameter: "The $\phi$-features of pronominal clitics block Agree and Attract operations of the probe complete T: yes/no." This accounts for differences between languages such as BP, French, Spanish and Standard Italian, which set the value 'yes' for this parameter, on the one hand, and languages like EP, Berber and Cypriot Greek, on the other hand.

If we assume that language development may be sensitive to computational cost, following, for example, a Derivational Complexity Metric, as proposed in Jakubowicz (2004), we expect children to produce in their earlier speech the pattern that is less complex, either enclisis or proclisis, according to the analysis. If one adopts an analysis where enclisis is the unmarked pattern and proclisis involves an additional movement, then proclisis should be harder to acquire than enclisis (Duarte and Matos, 2000). If, on the contrary, one adopts an analysis according to which proclisis involves less derivational steps, then proclisis should be easier than enclisis. However, if derivational complexity does not play a role, but input variability may delay language acquisition, we may find variable patterns of clitic placement in children's early productions: both proclisis and enclisis in enclitic and proclitic contexts.

\section{The acquisition of clitics: previous studies}

In the past years, there have been many studies on the acquisition of clitics, focusing mainly on clitic omission. These studies show that there is variation across languages in what concerns: i) clitic omission in early stages of language acquisition; ii) the rates of clitic omission; iii) the age period when clitic omission is found. In some languages, such as Spanish (Wexler et al., 2004; Fujino and Sano, 2002; Reglero and Ticio, 2003), Roumanian (Babyonyshev and Marin, 2005), Greek (Tsakali and Wexler, 2003), Serbo-Croatian (Ilic and Ud Deen, 2004), there is almost no clitic omission after two years old; in other languages, such as Italian (cf. Schaeffer, 2000), Catalan (cf. Wexler et al., 2004) or French (cf. Hamann et al., 1996; Jakubowicz et al., 1998; Grüter, 2006), there is clitic omission, which usually ends before 4 years old; finally, in languages such as EP, clitic omission is found until later ages (cf. Costa and Lobo, 2006, 2007a; Silva, 2008; Costa et al., 2009).

Furthermore, in languages with clitic omission, different types of clitics are omitted at different rates: pronominal accusative clitics are usually the most omitted; reflexive clitics, on the contrary, show very low rates of omission (cf. Jakubowicz et al., 1998) or cease to be omitted much earlier (cf. Costa and Lobo, 2007b; Silva, 2008).

The higher rates of clitic omission and the fact that omission lasts longer in EP led Costa and Lobo (2007a,b) to propose that clitic omission in EP is due to the availability of null objects in the adult grammar. Then, clitic omission in EP would correspond to an overgeneralization of null objects, since children omit clitics even in contexts where null objects are not allowed in the target grammar, such as islands or reflexive contexts. This hypothesis is supported by data from comprehension, which show that EP children, unlike French children (cf. Grüter, 2006), accept transitive readings in cases where the verb lacks an overt complement (cf. Costa and Lobo, 2009). EP speaking children know that the language allows null objects, but do not know yet the specific contexts where null objects are not allowed, specifically they do not know that null objects are variables (cf. Costa and Lobo, 2011).

In what concerns the acquisition of clitic placement, the literature is not so rich. Few studies consider the acquisition of clitic placement. As mentioned in the introduction, the acquisition literature reports that there are almost no clitic 
misplacements in the acquisition of French, Italian, Spanish or Standard Greek. Children seem to master the clitic pattern of the target language very early (see Guasti, 1993/94; Wexler et al., 2004; Hamann et al., 1996; Grüter, 2006; Marinis, 2000; among others).

For Cypriot Greek, however, some studies report deviant patterns of clitic placement in language acquisition. Petinou and Terzi (2002), in a study that includes data from five typically developing children, aged between 32 and 36 months, and five children with specific language impairment, aged between 48 and 60 months, show that young children generalize enclisis to proclisis contexts. More recently, based on an elicited production task with children acquiring Cypriot Greek, aged between 2;5 and 4;0, Neokleous (in press) shows that children under the age of three generalize enclisis to subjunctive proclisis contexts, but do not have deviant patterns in enclisis contexts. Clitic misplacement was no longer found with children older than three. While Petinou and Terzi (2002) interpret these results as overgeneralization of verb movement to a higher projection in early stages of Cypriot Greek, Neokleous (in press) attributes clitic misplacement to problems at the syntax-phonology interface.

In what concerns EP, previous studies based on spontaneous production data (see Duarte et al., 1995) mention that in early stages children generalize enclisis to proclisis contexts. According to the authors, clitic placement becomes stable by 48 months $^{6}$ : at this age, children already place most clitics preverbally in negation contexts and in clauses with overt complementizers.

In the written production of two groups of teenagers (around 12 and 14 years old), Santos (2002) shows that, in written elicited production tasks, there are few problems with clitic placement in proclisis and enclisis contexts in finite clauses. The main difficulties concern mesoclisis, which is far from being mastered in the 14 year old group (only $15 \%$ of correct answers). A similar finding is reported in Costa (2012). In a study with 10th grade students, the author run a task that required item transformation and students exhibited a success rate below $30 \%$ with mesoclisis. Both studies show, thus, that this pattern is not acquired spontaneously, but learnt with effort at school.

Although these studies report that problems with clitic placement are found mainly in proclitic contexts, in early stages, and in mesoclisis contexts, at school age, when we consider spontaneous production data by pre-schoolers we can find different types of patterns that do not conform to standard adult grammar: i) enclisis in proclisis contexts with subordinate clauses (15), with negation (16) and with wh-questions (17); ii) proclisis in enclisis contexts (18); iii) mesoclisis in the absence of future or conditional tenses (19); iv) clitic doubling ${ }^{7}$ (simultaneous proclisis and enclisis) $(20)^{8}$ :

a. Foste tu que daste-me (J. 4;8) [adult form: me deste]

Were you that gaveAGR2sg-CL1sg

'It was you that gave it to me'

b. Foi a Mariana que deu-me este. (S. 3;0.21; in Soares, 2006:375)

Was the Mariana that gave-CL1sg this

[adult form: $m e d e u$ ]

'It was Mariana that gave me this one'

c. foi alguém que meteu-me nesta fotografia. (J.G. 3;3; in Duarte et al., 1995)

was someone that put-CL1sg in_this picture

[adult form: me meteu]

'It was someone that took this picture from me'

(16) a. $O$ mano $\underline{\text { não }}$ deixa-me dormir (J. 3;8) [adult form: me deixa]

the brother not let-CL1sg sleep

'My brother does not let me sleep'

b. não chama-se nada (M. 20 m.; Duarte et al., 1995) [adult form: se chama]

not call-CL3refl nothing

'It is not called anything'

a. $\quad$ Porque partiu-se, mãe? (J. 3;4) [adult form: se partiu]

why broke-CL3refl, mommy

'Why did it break, mommy?'

\footnotetext{
${ }^{6}$ The authors take into account data from a corpus of spontaneous productions, transcribed according to CHILDES, made available by Dília Ramos Pereira. They do not mention the age of the children and how many children were considered in the corpus. We can infer from the children's citations that there are at least 6 children, with ages ranging from 19 months to 5 years.

7 By clitic doubling we mean the repetition of the same clitic both in proclisis and in enclisis.

8 The examples without bibliographic reference are taken from diary registers of a child from one of the authors.
} 
b. Porque é que foste-me interromper? (R., 2;5; in Duarte et al., 1995)

why is that go_2sg-CL1sg interrupt

[adult form: me foste]

'Why did you interrupt me?'

a. Uma carta me caiu, do pokémon (J. 4;8) [adult form: caiu-me]

A letter CL1sg fell, from_the pokemon

'One of the letters fell from my pokemon'

b. Se queres levar isto, eu te empresto. (J. 3;6) If

wantAGR2sg to_take this, I CL-2sg lendAGR1sg

[adult form: empresto-te]

'If you want to take this, I will lend it to you'

C. Eu te empresto um, pai. (J. 3;7) [adult form: empresto-te]

I CL2sg lend_AGR1sg one, daddy

'I will lend you one, daddy'

$\begin{array}{llllll}\text { a. } & \text { uá-me-s } & \text { uma moeda no meu porquinho? (J. 3; 4) } \\ \text { Give-CL1sg-AGR2sg a } & \text { coin in_the my little_pig }\end{array}$

[adult form: dás-me]

'Will you give me a coin for my little pig?'

b. Ai, duas pessoas a agarrar-m-em! (J. 3;5) [adult form: agarrarem-me]

Oh, two people to grab-CL1sg-AGR3pl

'Oh, two people grabbing me!'

c. Pai, deixa-me-s comer a sopa? (J. 3;5) [adult form: deixas-me]

Daddy, let-CL1sg-AGR2sg eat the soup

'Daddy, will you let me eat the soup?'

a. Eu disse que não se põe-se em pé. (J. 3;4)

I said that not CL3refl put-CL3refl in foot

[adult form: não se põe]

'I said that it does not stand'

b. não te engasgas-te nada! (R. 2;5; in Duarte et al., 1995)

not CL2sg choke-CL2sg nothing

[adult form: não te engasgas]

'You do not choke at all'

Since different patterns can be observed, for a better characterization of the development of clitic placement in EP, it is important to understand whether these are occasional productions or systematic patterns, how frequent these patterns are found in language acquisition and at what ages they can be found. In order to study the acquisition of clitic placement in a more controlled and systematic way, we designed an experiment, which will be described in the next section.

\section{The acquisition of clitic placement in EP: an elicitation task}

\subsection{Research questions and hypotheses}

Different complexity factors may play a role in the course of language acquisition. Complexity may be attributed to different properties. On the one hand, we expect structures that involve more complex derivations or more levels of embedding to be acquired later. On the other hand, more general syntactic properties should be easier to acquire than syntactic properties that are tied to specific lexical items. In this case, the variability of the input may delay language acquisition.

Considering that there are variable patterns of clitic placement in EP finite clauses and that these different patterns may be associated with different degrees of complexity, we may advance the following hypotheses for the acquisition of clitic placement:

i) If a variable input is problematic for language acquisition, we expect to find variable patterns of clitic placement both in enclisis contexts and in proclisis contexts; 
Table 1

Participants' data.

\begin{tabular}{llll}
\hline & Number & Age range & Mean age \\
\hline 5 year olds & 22 & $5 ; 0-5 ; 11$ & $5 ; 4$ \\
6 year olds & 20 & $6 ; 0-6 ; 10$ & $6 ; 4$ \\
7 year olds & 20 & $7 ; 1-7 ; 11$ & $7 ; 5$ \\
Adults & 20 & $19-40$ & 22 \\
\hline
\end{tabular}

ii) If language development is determined by derivational complexity factors and enclisis and proclisis are derived differently, we expect to find clitic misplacement in one of the contexts only - if proclisis corresponds to a more complex derivation, we expect children to generalize enclisis to proclisis contexts; if, on the contrary, enclisis corresponds to a more complex derivation, we expect children to generalize proclisis to enclisis contexts;

iii) If general syntactic properties are easier to acquire than syntactic properties that are tied to specific lexical items, we expect to find sensitivity to different contexts, according to their degree of complexity. If the acquisition of the contexts where proclisis is found is dependent on specific features of functional items, we expect to find differences between contexts and target clitic placement to be acquired earlier in contexts where proclisis is less tied to specific lexical items and linked instead to general syntactic features, such as in negation and in embedding contexts.

\subsection{Methodology}

To study the acquisition of clitic placement in EP, we built an elicited production task. Every participant was tested individually. Children were shown pictures in a computer and the researcher asked a question about the pictures or provided the beginning of a sentence that the participant had to complete. The stimulus did not contain clitics, in order to avoid a potential influence on the participant's answers. The interaction was recorded and the answers were transcribed. The test was run to 62 pre-school and first grade children, aged between 5 and 7 , as well as to a control group of 20 adults, monolingual speakers of EP from the Lisbon area, with no diagnosis of language or cognitive impairment. Details on the groups of participants are given in Table 1.

Since in EP clitic omission is still found at the age of 5, in order to make sure that children would produce clitics, we only included contexts with the clitic se. In fact, previous studies have shown that this clitic has lower rates of omission and ceases to be omitted earlier (Silva, 2008). We only included sentences with simple tenses, to avoid the additional position made available in complex predicates (Auxiliary-Verb). ${ }^{9}$ We did not include mesoclisis contexts, since, as reported in section 2, Santos (2002) and Costa (2012) show that this pattern requires explicit learning and is not mastered yet by adolescents.

The test included 36 items that induced the production of a sentence with a clitic in different proclisis contexts and in enclisis contexts, according to the following conditions:

i) simple clauses without a proclisis trigger (enclisis) - 8 items

ii) coordinate clauses without a proclisis trigger (enclisis) -4 items

iii) simple clauses with negation (proclisis) -4 items

iv) simple clauses with negative subjects - ninguém 'nobody' - (proclisis) - 4 items

v) simple clauses with quantified DPs with todos 'all' (proclisis) -4 items

vi) simple clauses with the preverbal adverb já 'already' (proclisis) - 4 items

vii) finite subordinate complement clauses to the verb querer 'want' (proclisis) - 4 items

viii) subordinate adverbial clauses with porque 'because' (proclisis) - 4 items.

The order of the items was randomized: items that induced clitics in preverbal position were mixed with items that induced clitics in postverbal position.

We give an example of some of the test items below.

\footnotetext{
${ }^{9}$ Even though we used sentences with simple tenses in the test, occasionally the participants have produced verbal structures with auxiliaries (e.g. foi sentar-se 'went to_sit-CL') instead of a simple tense (e.g. sentou-se 'sat-CL'). In those cases, we coded as 'other answers' the ones where there was doubt whether the clitic was proclitic to the non finite verb or enclitic to the auxiliary (e.g. foi se sentar 'went CL to_sit').
} 
Example of test item for simple clauses (enclisis):
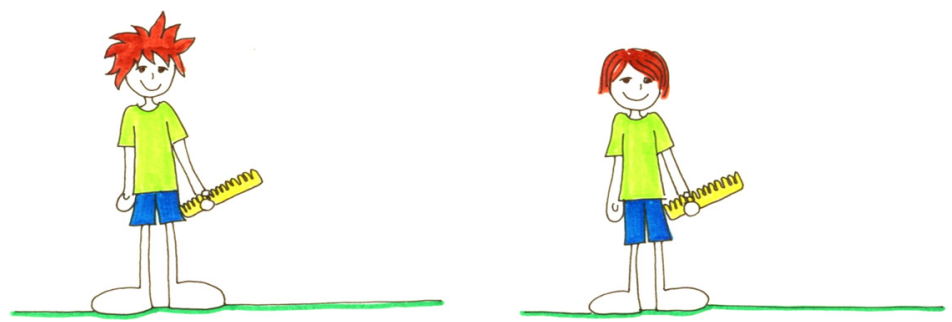

[picture 1] This boy is untidy. Look at his hair. But he has a comb.

[picture 2] What did the boy do?

Expected answer: Penteou-se.

combed-CL

'He combed himself'

Example of test item for negation contexts (proclisis):
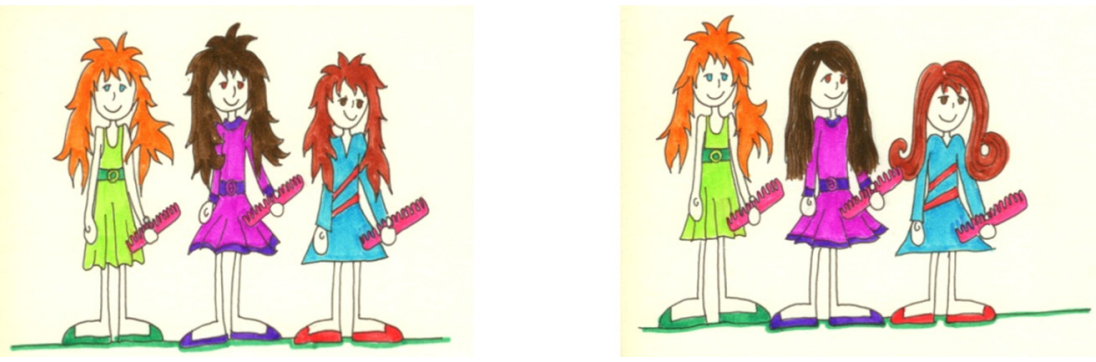

[picture 2] These two girls have used their comb and now they are tidy. But this girl is still untidy. What didn't she do? Expected answer: Não se penteou.

Not CL combed.

'She didn't comb herself'

Example of test item for finite subordinate complement clauses (proclisis):
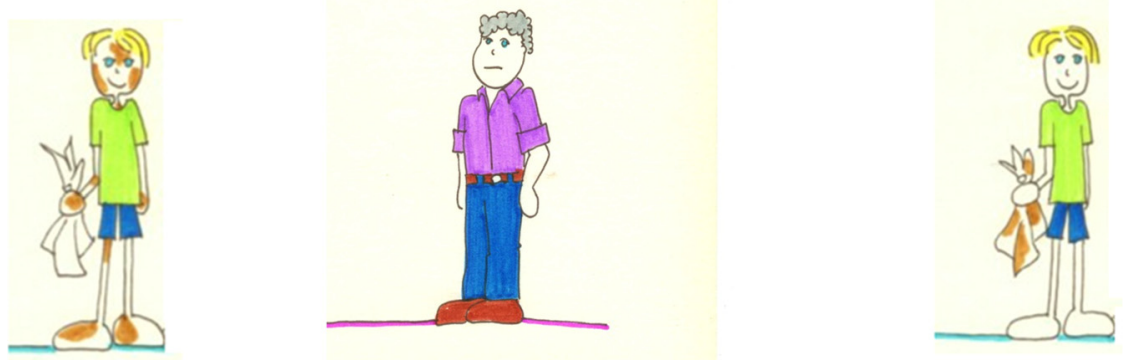

[picture 1] This boy went to the park and he got dirty. His daddy gave him a towel. What does daddy want that the boy do? Daddy wants...

Expected answer: que o menino/ele se limpe.

that the boy/he CL cleans

'Daddy wants the boy to clean himself'

In the items with the adverb, quantified subjects and negative subjects, to guarantee the presence of the proclisis trigger, the researcher provided the beginning of the answer followed by a suspensive intonation: Ninguém. . . 'Nobody. . .'; Todos os meninos. . 'All the boys. .'; Já. .. 'Already. . .' In the items with subordinate complement or adverbial clauses, the researcher provided the beginning of the sentence that the child had to complete. 
Table 2

Types of answers obtained in enclisis contexts.

\begin{tabular}{|c|c|c|c|c|c|}
\hline & \multicolumn{5}{|l|}{ Enclisis } \\
\hline & Enclisis & Proclisis & Doubling & Omission & Other \\
\hline 5 year olds & $69.2 \%$ & $0.4 \%$ & $0.4 \%$ & $5 \%$ & $25 \%$ \\
\hline 6 year olds & $89.2 \%$ & 0 & 0 & 0 & $10.8 \%$ \\
\hline 7 year olds & $92.5 \%$ & 0 & 0 & 0 & $7.5 \%$ \\
\hline Adults & $90.4 \%$ & 0 & 0 & $0.4 \%$ & $9.2 \%$ \\
\hline
\end{tabular}

Table 3

Types of answers obtained in proclisis contexts.

\begin{tabular}{|c|c|c|c|c|c|}
\hline & \multicolumn{5}{|l|}{ Proclisis } \\
\hline & Enclisis & Proclisis & Doubling & Omission & Other \\
\hline 5 year olds & $49.58 \%$ & $25.83 \%$ & $0.42 \%$ & $11.66 \%$ & $12.5 \%$ \\
\hline 6 year olds & $42.7 \%$ & $49.8 \%$ & 0 & $3.1 \%$ & $4.4 \%$ \\
\hline 7 year olds & $41.5 \%$ & $55.4 \%$ & 0 & $1.2 \%$ & $1.9 \%$ \\
\hline Adults & $10.83 \%$ & $86.04 \%$ & 0 & $0.42 \%$ & $2.71 \%$ \\
\hline
\end{tabular}

\subsection{Results}

We now turn to the results. First, the answers obtained were codified according to the following categories:

a) proclisis; b) enclisis; c) doubling; d) omission; e) other answers.

In the following tables, we present the global results, divided by age group, the conditions being arranged according to the target position of the clitic: enclisis (conditions i-ii) (Table 2) or proclisis (conditions iii-viii) (Table 3).

Considering the results presented in Tables 2 and 3, we can reach the following conclusions:

i) in enclisis contexts, there was almost no proclisis (only 1 case out of 264 in the 5 year old group);

ii) there was a high rate of enclisis in proclisis contexts in children from all age groups (above $40 \%$ );

iii) the control group also exhibits a small percentage of enclisis in proclisis contexts $(10.8 \%$, when we consider the global results);

iv) the rate of proclisis increases with age, the bigger difference being between 5 and 6 year olds;

v) doubling was very rare: there were only 3 cases of doubling and only in the 5 year old group ${ }^{10}$;

vi) omission was residual, which shows that targeting se clitics was an effective strategy: only in the 5 year old group was there a rate of omission slightly above $5 \%(68 / 792-8.6 \%)$;

vii) other answers were obtained, mostly with the items that induced proclisis in coordinate structures, which methodologically did not work as well as the other items.

If we maintain only enclisis and proclisis answers, ignoring the other responses, we obtain the following results ${ }^{11}$ :

The results in Table 4 show that there are no problems in enclitic contexts - all groups place clitics in postverbal position (rates above 99\%) - but there are deviant patterns of clitic placement in proclisis contexts. Globally, there is a developmental jump from the 5 year old group (36\% proclisis) to the 6 year old group (53\% proclisis), and a smaller increase in proclisis rates from the 6 year old group to the 7 year old group $(57.2 \%)$. Crucially, even the control group of adults did not have ceiling performances: the proclisis rate is below $90 \%(88 \%)$.

\footnotetext{
${ }^{10}$ Two of these cases occur in proclisis contexts (one with negation, the other with the adverb já) and the third one occurs in an enclitic context where the child used a verbal complex instead of a simple tense:

(i) não se escondeu-se 'not CL hid-CL'

(ii) já se levantou-se 'already CL got_up-CL'

(iii) a avó foi-se pentear-se 'the grandmother went-CL to_comb-CL'

${ }^{11}$ The number of answers with either enclisis or proclisis, for each age group, is the following: adults: $217 / 240$ in enclisis contexts; $465 / 480$ in proclisis contexts; 5 year olds: $186 / 264$ for enclisis contexts; $408 / 528$ for proclisis contexts; 6 year olds: $214 / 240$ for enclisis contexts; $444 / 480$ for proclisis contexts; 7 year olds: $222 / 240$ for enclisis contexts; $465 / 480$ for proclisis contexts.
} 
Table 4

Global results, collapsing enclisis contexts and proclisis contexts, considering only answers with clitics.

\begin{tabular}{lllll}
\hline & \multicolumn{2}{c}{ Enclisis contexts } & Proclisis contexts \\
\cline { 2 - 3 } & Enclisis & Proclisis & Enclisis \\
\hline 5 year olds & $99.5 \%$ & $0.5 \%$ & $64 \%$ & $36 \%$ \\
6 year olds & $100 \%$ & 0 & $46.2 \%$ & $53.8 \%$ \\
7 year olds & $100 \%$ & 0 & $42.8 \%$ & $57.2 \%$ \\
Adults & $100 \%$ & 0 & $11.2 \%$ & $88.8 \%$ \\
\hline
\end{tabular}

Table 5

Rates of proclisis in each age group by proclisis context.

\begin{tabular}{lllll}
\hline & 5 year olds & 6 year olds & 7 year olds & Adults \\
\hline Negation & $61 \%$ & $87.5 \%$ & $84.4 \%$ & $97.4 \%$ \\
Negative subjects & $48.3 \%$ & $69.2 \%$ & $70.9 \%$ & $96.1 \%$ \\
Complement clauses & $46.7 \%$ & $74.6 \%$ & $65.8 \%$ & $97.3 \%$ \\
Adverb já 'already' & $36 \%$ & $58.2 \%$ & $65.8 \%$ & $93.6 \%$ \\
Adverbial clauses & $14 \%$ & $20 \%$ & $32.9 \%$ & $77.6 \%$ \\
Quantified subjects & $9.9 \%$ & $12.2 \%$ & $21.3 \%$ & $70.8 \%$ \\
\hline
\end{tabular}

Since only proclisis contexts are problematic, we need to consider each proclisis context, in order to investigate whether the deviant patterns are distributed evenly across the different contexts or whether some specific contexts are causing proclisis rates to drop. Table 5 presents the rates of proclisis obtained in each context designed to elicit proclisis, according to age group.

As can be seen in Table 5, the rates of proclisis are not the same across the different contexts. There are high rates of proclisis in some contexts, but low rates in others. The control group only has rates below $90 \%$ in two contexts - adverbial clauses and quantified subjects, where rates of proclisis are between $70 \%$ and $80 \%$.

The rates of proclisis increase in all contexts from the 5 year old group to the 6 year old group. In the 5 year old group, proclisis rates are above $50 \%$ only in negation contexts. There are not many differences between the 6 year olds and the 7 year olds: in these two groups, the rates of proclisis are above $80 \%$ in negation contexts; only in adverbial clauses and with quantified subjects are the rates of proclisis below $50 \%$. However, we can observe a slight increase in the rates of proclisis in these two last contexts in the 7 year old group.

We can, thus, observe that the order of acquisition of proclisis in the different contexts, starting with the contexts where proclisis is acquired earlier, follows this scale:

1. negation $>2$. negative subjects/finite complement clauses $>3$. adverb já 'already'>

4. finite adverbial clauses $>5$. quantified subjects

Let us now consider the individual results by age group.

In the table with the individual results, we give for each proclisis context the number of items with proclisis $(=P)$ and with enclisis (=E). The proclisis contexts are abbreviated as follows: QSubj = Quantified Subjects; SubAdv = Finite Adverbial Subordinate Clause; Adv = Clauses with Adverb já 'already'; Compl = Finite Complement clauses; NegSubj = Clauses with a negative subject; Neg = Clauses with negation. The participants are ranked according to their performance: from those with higher rates of proclisis to those with lower rates of proclisis.

The individual results from adults (Table 6) show that there is variation between participants and, in some cases, in a same individual: 7 adults (1-7) place the clitic preverbally in a categorical way; 2 adults (19-20) have almost identical rates of proclisis and enclisis; the others have residual cases of enclisis, although they never place the clitic postverbally with negation and negative subjects. ${ }^{12}$

Let us now consider the individual results of the 5 year old group:

As can be seen in Table 7 above, two of the 5 year old children (21-22) have massive clitic omission. This is the reason why we included 22 subjects in this group. The other children produce clitics, but there is variation in this group concerning the position of the clitic with respect to the verb. A single child (1) places all the clitics in proclisis, just as expected in the

\footnotetext{
$\overline{12}$ Although this is a group of young adults (mean age 22), there does not seem to be a correlation between the preference for enclisis and age: the two adults that are more enclitic are older than the mean age.
} 
Table 6

Adults' individual results in proclisis contexts.

\begin{tabular}{|c|c|c|c|c|c|c|c|c|c|c|c|c|c|c|c|c|}
\hline \multirow[b]{2}{*}{ Adults } & P & $\mathrm{E}$ & $\mathrm{P}$ & $\mathrm{E}$ & $\mathrm{P}$ & E & & $\mathrm{P}$ & $E$ & $\mathrm{P}$ & $\mathrm{E}$ & $P$ & E & & $P$ & E \\
\hline & \multicolumn{2}{|c|}{ Q Subj } & \multicolumn{2}{|c|}{ Sub Adv } & \multicolumn{3}{|c|}{ Adv } & \multicolumn{2}{|c|}{ Compl } & \multicolumn{2}{|c|}{ Neg Subj } & \multicolumn{3}{|c|}{$\mathrm{Neg}$} & \multicolumn{2}{|c|}{ Total } \\
\hline 1 & 4 & 0 & 4 & 0 & & 4 & 0 & 3 & 0 & 4 & 0 & & 4 & 0 & 23 & 0 \\
\hline 2 & 4 & 0 & 4 & 0 & & 4 & 0 & 4 & 0 & 3 & 0 & & 4 & 0 & 23 & 0 \\
\hline 3 & 4 & 0 & 4 & 0 & & 4 & 0 & 4 & 0 & 4 & 0 & & 4 & 0 & 24 & 0 \\
\hline 4 & 4 & 0 & 4 & 0 & & 4 & 0 & 3 & 0 & 4 & 0 & & 4 & 0 & 23 & 0 \\
\hline 5 & 4 & 0 & 4 & 0 & & 4 & 0 & 4 & 0 & 4 & 0 & & 4 & 0 & 24 & 0 \\
\hline 6 & 4 & 0 & 4 & 0 & & 4 & 0 & 4 & 0 & 4 & 0 & & 4 & 0 & 24 & 0 \\
\hline 7 & 4 & 0 & 4 & 0 & & 4 & 0 & 4 & 0 & 4 & 0 & & 4 & 0 & 24 & 0 \\
\hline 8 & 3 & 1 & 4 & 0 & & 3 & 0 & 4 & 0 & 4 & 0 & & 4 & 0 & 22 & 1 \\
\hline 9 & 3 & 1 & 4 & 0 & & 4 & 0 & 4 & 0 & 4 & 0 & & 4 & 0 & 23 & 1 \\
\hline 10 & 4 & 0 & 2 & 0 & & 3 & 1 & 4 & 0 & 4 & 0 & & 3 & 0 & 20 & 1 \\
\hline 11 & 2 & 1 & 4 & 0 & & 4 & 0 & 3 & 1 & 4 & 0 & & 4 & 0 & 21 & 2 \\
\hline 12 & 4 & 0 & 2 & 2 & & 4 & 0 & 4 & 0 & 4 & 0 & & 4 & 0 & 22 & 2 \\
\hline 13 & 4 & 1 & 4 & 0 & & 4 & 0 & 3 & 0 & 3 & 0 & & 4 & 0 & 22 & 1 \\
\hline 14 & 2 & 2 & 2 & 1 & & 4 & 0 & 4 & 0 & 4 & 0 & & 4 & 0 & 20 & 3 \\
\hline 15 & 1 & 3 & 3 & 1 & & 3 & 1 & 4 & 0 & 4 & 0 & & 4 & 0 & 19 & 5 \\
\hline 16 & 1 & 3 & 3 & 1 & & 4 & 0 & 4 & 0 & 4 & 0 & & 4 & 0 & 20 & 4 \\
\hline 17 & 4 & 0 & 1 & 3 & & 4 & 0 & 3 & 0 & 4 & 0 & & 4 & 0 & 20 & 3 \\
\hline 18 & 0 & 4 & 2 & 2 & & 4 & 0 & 3 & 0 & 4 & 0 & & 4 & 0 & 17 & 6 \\
\hline 19 & 0 & 4 & 1 & 3 & & 3 & 1 & 4 & 0 & 1 & 3 & & 3 & 1 & 12 & 12 \\
\hline 20 & 1 & 3 & 0 & 4 & & 2 & 2 & 3 & 1 & 3 & 0 & & 3 & 1 & 12 & 11 \\
\hline
\end{tabular}

Table 7

5 year olds' individual results in proclisis contexts.

\begin{tabular}{|c|c|c|c|c|c|c|c|c|c|c|c|c|c|c|c|}
\hline \multirow[b]{2}{*}{5 y.o. } & P & E & P & $E$ & $\mathrm{P}$ & $\mathrm{E}$ & & $\mathrm{P}$ & E & $\mathrm{P}$ & $E$ & $P$ & E & $\mathrm{P}$ & E \\
\hline & \multicolumn{2}{|c|}{ Q Subj } & \multicolumn{2}{|c|}{ Sub Adv } & \multicolumn{3}{|c|}{ Adv } & \multicolumn{2}{|c|}{ Compl } & \multicolumn{2}{|c|}{ Neg Subj } & \multicolumn{2}{|c|}{ Neg } & \multicolumn{2}{|c|}{ Total } \\
\hline 1 & 3 & 0 & 4 & 0 & & 4 & 0 & 3 & 0 & 4 & 0 & 4 & 0 & 22 & 0 \\
\hline 2 & 3 & 0 & 0 & 2 & & 4 & 0 & 3 & 0 & 4 & 0 & 4 & 0 & 18 & 2 \\
\hline 3 & 1 & 3 & 0 & 2 & & 2 & 2 & 4 & 0 & 3 & 0 & 4 & 0 & 14 & 7 \\
\hline 4 & 0 & 3 & 1 & 3 & & 2 & 1 & 2 & 2 & 3 & 0 & 4 & 0 & 12 & 9 \\
\hline 5 & 0 & 4 & 1 & 2 & & 2 & 2 & 2 & 1 & 2 & 0 & 4 & 0 & 11 & 9 \\
\hline 6 & 0 & 4 & 1 & 3 & & 2 & 1 & 4 & 0 & 3 & 1 & 4 & 0 & 14 & 9 \\
\hline 7 & 0 & 4 & 4 & 0 & & 1 & 3 & 2 & 1 & 3 & 0 & 3 & 1 & 13 & 9 \\
\hline 8 & 0 & 4 & 1 & 1 & & 3 & 0 & 2 & 0 & 1 & 0 & 2 & 2 & 9 & 7 \\
\hline 9 & 0 & 3 & 0 & 3 & & 3 & 1 & 1 & 1 & 3 & 0 & 3 & 1 & 10 & 9 \\
\hline 10 & 0 & 4 & 1 & 3 & & 0 & 4 & 3 & 1 & 1 & 2 & 4 & 0 & 9 & 14 \\
\hline 11 & 0 & 4 & 0 & 4 & & 2 & 0 & 1 & 3 & 1 & 2 & 3 & 1 & 7 & 14 \\
\hline 12 & 0 & 4 & 0 & 4 & & 1 & 3 & 0 & 4 & 1 & 1 & 2 & 2 & 4 & 18 \\
\hline 13 & 0 & 4 & 0 & 3 & & 0 & 4 & 0 & 3 & 0 & 1 & 2 & 1 & 2 & 16 \\
\hline 14 & 0 & 3 & 0 & 4 & & 0 & 4 & 1 & 2 & 0 & 4 & 0 & 2 & 1 & 19 \\
\hline 15 & 0 & 2 & 0 & 4 & & 0 & 4 & 0 & 1 & 0 & 4 & 1 & 3 & 1 & 18 \\
\hline 16 & 0 & 4 & 0 & 3 & & 0 & 3 & 0 & 4 & 0 & 3 & 1 & 2 & 1 & 19 \\
\hline 17 & 0 & 4 & 0 & 4 & & 0 & 4 & 0 & 4 & 0 & 4 & 1 & 3 & 1 & 23 \\
\hline 18 & 0 & 4 & 0 & 3 & & 0 & 4 & 0 & 1 & 0 & 3 & 0 & 4 & 0 & 19 \\
\hline 19 & 0 & 2 & 0 & 1 & & 0 & 4 & 0 & 3 & 0 & 3 & 0 & 3 & 0 & 16 \\
\hline 20 & 0 & 2 & 0 & 2 & & 0 & 4 & 0 & 1 & 0 & 3 & 0 & 4 & 0 & 16 \\
\hline 21 & 0 & 2 & 0 & 1 & & 1 & 0 & 0 & 0 & 0 & 0 & 1 & 1 & 2 & 4 \\
\hline 22 & 0 & 0 & 0 & 0 & & 0 & 0 & 0 & 0 & 0 & 0 & 0 & 0 & 0 & 0 \\
\hline
\end{tabular}

standard adult grammar. 3 children only have enclisis (18-20); 8 children still have a majority of enclisis (10-17) and 8 children already have predominant proclisis (2-9). For the children who produce both proclisis and enclisis, the contexts with negation and negative subjects are the ones where proclisis rates are higher.

When we consider the individual results for the 6 year olds, we can observe a clear development with respect to the 5-year olds (Table 8).

Although we continue to find variation between proclisis and enclisis, the number of children who place the clitic predominantly in preverbal position increases: 13 (1-13). Again, the contexts where proclisis rates are higher are the contexts with negation and negative subjects.

Let us now consider the individual results for the 7 year old group. 
Table 8

6 year olds' individual results in proclisis contexts.

\begin{tabular}{|c|c|c|c|c|c|c|c|c|c|c|c|c|c|c|}
\hline & $\mathrm{P}$ & & $\mathrm{P}$ & E & $\mathrm{P}$ & E & $\mathrm{P}$ & E & $\mathrm{P}$ & $\mathrm{E}$ & $\mathrm{P}$ & E & $\mathrm{P}$ & E \\
\hline 6 y.o. & Q Subj & & Sub & Adv & Adv & & Comp & & Neg $\mathrm{S}$ & Subj & Neg & & Total & \\
\hline 1 & 4 & 0 & 3 & 1 & 4 & 0 & 4 & 0 & 4 & 0 & 4 & 0 & 23 & 1 \\
\hline 2 & 0 & 4 & 3 & 1 & 2 & 2 & 4 & 0 & 4 & 0 & 4 & 0 & 17 & 7 \\
\hline 3 & 2 & 2 & 0 & 4 & 3 & 1 & 4 & 0 & 4 & 0 & 4 & 0 & 17 & 7 \\
\hline 4 & 0 & 4 & 1 & 3 & 4 & 0 & 4 & 0 & 4 & 0 & 4 & 0 & 17 & 7 \\
\hline 5 & 1 & 3 & 2 & 2 & 4 & 0 & 2 & 2 & 4 & 0 & 4 & 0 & 17 & 7 \\
\hline 6 & 0 & 4 & 2 & 2 & 3 & 1 & 2 & 0 & 4 & 0 & 4 & 0 & 15 & 7 \\
\hline 7 & 1 & 3 & 0 & 3 & 3 & 1 & 4 & 0 & 4 & 0 & 3 & 0 & 15 & 7 \\
\hline 8 & 1 & 2 & 0 & 3 & 2 & 2 & 3 & 0 & 4 & 0 & 4 & 0 & 14 & 7 \\
\hline 9 & 0 & 4 & 1 & 2 & 4 & 0 & 3 & 1 & 3 & 1 & 1 & 1 & 12 & 9 \\
\hline 10 & 0 & 4 & 0 & 4 & 3 & 1 & 4 & 0 & 3 & 1 & 4 & 0 & 14 & 10 \\
\hline 11 & 0 & 4 & 0 & 4 & 3 & 1 & 4 & 0 & 3 & 1 & 3 & 1 & 13 & 11 \\
\hline 12 & 0 & 4 & 2 & 1 & 2 & 2 & 3 & 1 & 2 & 2 & 4 & 0 & 13 & 10 \\
\hline 13 & 0 & 4 & 0 & 3 & 3 & 1 & 1 & 2 & 4 & 0 & 3 & 0 & 11 & 10 \\
\hline 14 & 0 & 4 & 0 & 4 & 3 & 1 & 2 & 2 & 2 & 2 & 4 & 0 & 11 & 13 \\
\hline 15 & 0 & 3 & 0 & 1 & 1 & 3 & 0 & 2 & 0 & 3 & 1 & 0 & 2 & 12 \\
\hline 16 & 0 & 3 & 0 & 3 & 1 & 3 & 3 & 1 & 1 & 3 & 4 & 0 & 9 & 13 \\
\hline 17 & 0 & 3 & 0 & 4 & 1 & 3 & 3 & 1 & 1 & 3 & 1 & 3 & 6 & 17 \\
\hline 18 & 0 & 4 & 0 & 3 & 0 & 4 & 2 & 2 & 1 & 3 & 2 & 2 & 5 & 18 \\
\hline 19 & 0 & 2 & 0 & 4 & 0 & 3 & 1 & 1 & 1 & 2 & 2 & 0 & 4 & 12 \\
\hline 20 & 0 & 4 & 0 & 3 & 0 & 4 & 0 & 3 & 1 & 3 & 1 & 2 & 2 & 19 \\
\hline
\end{tabular}

Table 9

7 year olds' individual results in proclisis contexts.

\begin{tabular}{|c|c|c|c|c|c|c|c|c|c|c|c|c|c|c|}
\hline \multirow{3}{*}{$\begin{array}{l}7 \text { y.o. } \\
1\end{array}$} & $\mathrm{P}$ & E & $\mathrm{P}$ & $\mathrm{E}$ & $\mathrm{P}$ & $E$ & $\mathrm{P}$ & $E$ & $\mathrm{P}$ & E & $\mathrm{P}$ & E & $\mathrm{P}$ & $E$ \\
\hline & \multicolumn{2}{|c|}{ Q Subj } & \multicolumn{2}{|c|}{ Sub Adv } & \multicolumn{2}{|c|}{ Adv } & \multicolumn{2}{|c|}{ Compl } & \multicolumn{2}{|c|}{ Neg Subj } & \multicolumn{2}{|c|}{ Neg } & \multicolumn{2}{|c|}{ Total } \\
\hline & 4 & 0 & 4 & 0 & 4 & 0 & 4 & 0 & 4 & 0 & 4 & 0 & 24 & 0 \\
\hline 2 & 4 & 0 & 3 & 1 & 4 & 0 & 4 & 0 & 4 & 0 & 4 & 0 & 23 & 1 \\
\hline 3 & 2 & 2 & 3 & 1 & 4 & 0 & 4 & 0 & 4 & 0 & 4 & 0 & 21 & 3 \\
\hline 4 & 3 & 1 & 3 & 1 & 4 & 0 & 4 & 0 & 4 & 0 & 4 & 0 & 22 & 2 \\
\hline 5 & 2 & 2 & 3 & 1 & 3 & 1 & 4 & 0 & 4 & 0 & 4 & 0 & 20 & 4 \\
\hline 6 & 0 & 2 & 2 & 2 & 4 & 0 & 3 & 1 & 4 & 0 & 4 & 0 & 17 & 5 \\
\hline 7 & 0 & 4 & 2 & 2 & 3 & 1 & 4 & 0 & 4 & 0 & 4 & 0 & 17 & 7 \\
\hline 8 & 1 & 3 & 1 & 3 & 3 & 1 & 4 & 0 & 4 & 0 & 4 & 0 & 17 & 7 \\
\hline 9 & 0 & 4 & 1 & 3 & 4 & 0 & 4 & 0 & 3 & 1 & 4 & 0 & 16 & 8 \\
\hline 10 & 0 & 4 & 1 & 3 & 4 & 0 & 3 & 1 & 2 & 2 & 4 & 0 & 14 & 10 \\
\hline 11 & 0 & 4 & 0 & 4 & 2 & 2 & 3 & 1 & 4 & 0 & 4 & 0 & 13 & 11 \\
\hline 12 & 0 & 4 & 0 & 4 & 2 & 2 & 3 & 1 & 4 & 0 & 3 & 1 & 12 & 12 \\
\hline 13 & 0 & 4 & 1 & 3 & 2 & 2 & 1 & 3 & 2 & 2 & 4 & 0 & 10 & 14 \\
\hline 14 & 0 & 3 & 1 & 3 & 2 & 2 & 2 & 2 & 2 & 2 & 2 & 1 & 9 & 13 \\
\hline 15 & 0 & 4 & 0 & 4 & 2 & 2 & 2 & 2 & 2 & 2 & 3 & 1 & 9 & 15 \\
\hline 16 & 0 & 4 & 0 & 4 & 3 & 1 & 1 & 3 & 4 & 0 & 3 & 1 & 11 & 17 \\
\hline 17 & 0 & 4 & 0 & 3 & 1 & 3 & 1 & 3 & 1 & 3 & 4 & 0 & 7 & 16 \\
\hline 18 & 0 & 4 & 0 & 4 & 1 & 3 & 1 & 3 & 0 & 4 & 2 & 2 & 4 & 20 \\
\hline 19 & 0 & 4 & 0 & 3 & 0 & 3 & 0 & 3 & 0 & 3 & 0 & 3 & 0 & 19 \\
\hline 20 & 0 & 4 & 0 & 4 & 0 & 4 & 0 & 4 & 0 & 4 & 0 & 4 & 0 & 24 \\
\hline
\end{tabular}

As can be seen in Table 9, two children (19-20) are responsible for the fact that the global results for this group are a little bit lower than expected, since they do not produce any clitic in preverbal position. The results for this group are not much different from those of the 6 year old group. We observe, however, that there is a larger number of children that places clitics preverbally in the "difficult" contexts, namely with quantified subjects and in adverbial clauses.

Therefore, the individual results confirm what we have observed for the groups as a whole: although there is variation between participants, the scale of complexity is maintained at the individual level.

\section{Discussion}

Returning to the research questions stated above, we may conclude that, globally, our study confirms previous results based on spontaneous production data (Duarte et al., 1995). We can also observe that problems with clitic placement are 
independent from clitic omission: 6 and 7 year olds show almost no omission, but they still have high rates of enclisis generalization. Our study also shows that overuse of enclisis in EP lasts longer than in other languages. 6 and 7 year olds still generalize enclisis. This does not happen in Cypriot Greek, where proclisis seems to be already acquired at age of 4 (cf. Neokleous, in press).

Considering the hypotheses formulated in section 2, we may conclude that: hypothesis i) does not hold, since children do not overuse proclisis in enclisis contexts. In what concerns hypothesis ii), we may conclude that in the acquisition of EP there is overuse of enclisis in proclisis contexts, but the opposite does not happen. If this is the result of derivational complexity, these data are consistent with Duarte et al.'s hypothesis.

As for hypothesis iii), our study has shown that it is borne out, since we have discovered that the acquisition of clitic placement develops at different rates in different proclisis contexts. This is the most interesting finding of our study.

As described in the previous section, there are contexts where proclisis is acquired earlier and contexts where proclisis is acquired later. Recall the scale of development that we presented above:

1. negation $>2$. negative subjects / finite complement clauses $>3$. adverb já 'already' $>4$. finite adverbial clauses $>5$. quantified subjects

How does complexity explain this developmental scale?

Our hypothesis is that variation associated with each syntactic context delays acquisition. In fact, there are studies on other structures and other languages that show that variation in the system may determine developmental delays. Costa and Lobo (2011) have shown that EP-speaking children have a slower development in clitic production, possibly due to the availability of null objects in the adult grammar. Differently from languages that have no variation between clitics and null objects, EP-speaking children omit clitics in contexts where clitic omission is not possible. Interestingly, the rates of clitic omission are not the same everywhere: children distinguish non-reflexive clitics in simple clauses from reflexive clitics and from island contexts. Other authors have argued that input variability causes delays in acquisition: Miller and Schmitt (2010) have shown that the variation in the overt marking of plural morphology in the nominal domain determines a slower development of plural identification.

When we look at the different proclisis contexts included in our experiment, we observe that there are contexts where the morphosyntactic clues are more salient. The more general the feature (that is, the more it is independent from lexical specification), the more stable the system in a specific context and the more precocious its acquisition.

Let us consider the different contexts included in our experiment:

a) negation: negative clauses are clauses where proclisis is categorical; the [negative] feature is a syntactic feature that is acquired very early;

b) negative subjects: not all subjects induce proclisis, but every subject with a [negative] feature induces proclisis;

c) subordinate complement clauses: not all embedded contexts display proclisis; there is variation between finite and infinitival clauses and we can find cases of enclisis in the adult grammar in embedded clauses with the indicative; however, embedded clauses with the subjunctive headed by an overt complementizer, such as the ones included in the experiment, are more clearly marked as finite subordinate clauses where proclisis is required, with distinctive properties with respect to root contexts; children will have to determine the subset of embedded contexts that have obligatory proclisis ${ }^{13}$

d) adverbs: as is well known, only a subset of preverbal adverbs, with variable semantic properties, trigger proclisis (e.g. Castro and Costa, 2003); the child will have to determine for each specific adverb the grammatical features associated with the adverbs that trigger proclisis;

e) quantified subjects: as described in the literature, not all quantified subjects induce proclisis (e.g. Martins, 1994); although universally quantified subjects with todos 'all' are usually proclisis triggers, the child will have to determine the subset of quantifiers that acts as a proclisis trigger;

f) adverbial clauses: reason clauses, such as the ones included in the experiment, as described by several authors (e.g. Lobo, 2003), may have an ambiguous syntactic behaviour; they may be closer to coordinate structures; this is thus a syntactic context less clearly marked as embedded and more prone to variation between proclisis and enclisis. ${ }^{14}$

Summarizing, globally the contexts where proclisis is acquired later are contexts where there is more variation between specific lexical items or whose syntactic status may be ambiguous, confirming hypothesis iii).

\footnotetext{
$\overline{13}$ Notice that in the study of Flores and Barbosa (2012), with Portuguese heritage speakers and a control group of monolingual children, the context where proclisis was less categorical were subordinate clauses with the indicative.

${ }^{14}$ In fact, we can find some variation in clitic placement in because-clauses in the adult grammar. This can possibly be due to the ambiguous syntactic status of these clauses. It would be interesting to see whether this variable pattern also holds for other types of adverbial clauses.
} 
Interestingly, the contexts where we find more instability in adults and where proclisis is acquired later by children are also contexts where proclisis was not completely categorical in older stages of Portuguese. Therefore, to some extent, the acquisition data mirror the adults' grammatical system.

As described in Martins (2011), there was some degree of variation in clitic placement in older stages of Portuguese. With negation and negative subjects, we only find proclisis, but with quantified subjects and some adverbs there are some cases of enclisis in contexts that are predominantly proclitic ${ }^{15}$ :

a. et todolos da oste marauillarõse moyto [Ogando, 1980:258]

and all-the of.the group wonderedCL3refl much

'and all from the group became very astonished'

b. todos sse queixavom ao abbade [13/14th c. VS6]

all CL3refl complained to.the abbot

'they all complained to the abbot'

a. et el outrosi asanauase cõtra ellas moy mal [Ogando, 1980] and he instead raiseCL3refl against them very badly

'and he instead fought against them very hardly'

b. Outrossi lles dou todo o meu herdamento [1281 HGP055]

Instead CLthem give all the my heritage

'I will give them instead all the heritage I have'

\section{a. Item quitome a San Saluador de Nozedo [1290 HGP058]}

likewise leaveCLme to San Salvador de Nozedo...

'So I leave to San Salvador de Nozedo'

b. Item Ihes perguntarom quanto valja [1414 DN159]

likewise CLthem asked how_much was_worth...

'So they have been asked how much it was worth'

Martins $(2011)^{16}$ also reports some variation in complement clauses with the indicative, that is stable diachronically and that is visible in Old Portuguese texts, in Portuguese texts from the 16th to 20th centuries, and in different varieties of Portuguese (non standard varieties of EP and African varieties).

As said in Martins (2011:97), the description of data from different corpora shows that there is marginal variation in clitic placement in contexts that are typically proclitic. This variation is quantitatively low and diachronically stable: diachronically, there are no changes or diminishment of proclitic contexts, but there is a notably stable amount of enclisis in specific proclitic environments.

It seems, then, that grammatical systems are sensitive to the specification of lexical items and to the ambiguity between root and embedded contexts. Some contexts are more stable than others in what concerns proclisis and children's development reflects this pattern.

To conclude, we have shown that clitic placement in EP contrasts with other word order phenomena that are acquired very early. We have also shown that the developmental path is not identical across contexts. We have proposed that variation is context-sensitive, and it can be explained in terms of specification - the more lexically specified contexts are the less categorical. Therefore, adult performance and diachronic data are two independent sources for testifying the same tendency for variation. The acquisition path mirrors the adult tendencies. However, more than an effect of frequency, the acquisition of clitic placement mirrors the input variability associated with specific contexts: children are sensitive to contexts with more or less variation between lexical items. We hypothesize, then, that the specificity of lexical items may be the factor explaining the delay in acquisition.

However, the one-way tendency shows that this is not a reflex of a general variable input, but it is conditioned by grammatical and lexical factors. The different rates of proclisis found in different contexts show that an overall explanation for the generalization of enclisis (e.g. less complex derivation or change in the morphological status of the clitic) is not plausible.

\footnotetext{
${ }^{15}$ According to Martins (2011:88), proclisis contexts are stable diachronically (cf. Martins, 1994), but, on the other hand, the array of advebs that trigger proclisis is not so stable.

${ }^{16}$ According to Martins (2011:96), although enclisis in subordinate finite clauses is uncommon, it is attested in Old Portuguese, in Portuguese from the XVIth to the XIXth century, in the first half of the XXth century, and in contemporary Portuguese, including, literary Portuguese, dialect Portuguese and the African varieties of Portuguese.
} 


\section{Acknowledgments}

We would like to thank Stéphanie Dias Vaz and Mariana Silva for their help with data collection. This research was carried out within the project "Syntactic Dependencies from 3 to 10" [PTDC/CLE-LIN/099802/2008], funded by Fundação para a Ciência e a Tecnologia.

\section{References}

Babyonyshev, M., Marin, S., 2005. The acquisition of object clitic constructions in Romanian. In: Scott Gess, R., Rubin, E.J. (Eds.), Theoretical and Experimental Approaches to Romance Linguistics. John Benjamins, Amsterdam, pp. 21-40.

Barbosa, P., 1996. Clitic Placement in European Portuguese and the Position of Subjects. In: Halpern, A., Zwicky, A. (Eds.), Approaching Second: Second Position Clitics and Related Phenomena. CSLI Publications, Stanford, CA, pp. 1-40.

Castro, A., Costa, J., 2003. Weak forms as X: prenominal possessives and preverbal adverbs in Portuguese. In: Pérez-Leroux, A.T., Roberge, Y (Eds.), Romance Linguistics: Theory and Acquisition. John Benjamins, Amsterdam \& Philadelphia, pp. 95-110.

Costa, A.L., 2012. A mesóclise: uma espécie linguística em vias de extinção, ms.

Costa, J., Lobo, M., 2006. A aquisição de clíticos em PE: Omissão de Clíticos ou Objectos Nulos? In: XXI Encontro Nacional da APL. Textos Seleccionados. APL, Lisboa, pp. 285-293.

Costa, J., Lobo, M., 2007a. Clitic Omission, null objects or both in the acquisition of European Portuguese? In: Baauw, S., Drijkonongen, F., Pinto, M. (Eds.), Romance Languages and Linguistic Theory 2005. John Benjamins, Amsterdam, pp. 59-72.

Costa, J., Lobo, M., 2007b. Complexidade e omissão de clíticos: o caso dos reflexos. In: XXII Encontro Nacional da APL. Textos seleccionados. APL, Lisboa, pp. 303-313.

Costa, J., Lobo, M., 2009. Clitic omission in the acquisition of European Portuguese: data from comprehension. In: Pires, A., Rothman, J. (Eds.), Minimalist Inquiries into Child Language Acquisition. Case Studies Across Portuguese. Mouton de Gruyter, Berlin/New York, pp. 63-84.

Costa, J., Lobo, M., 2011. Objeto nulo na aquisição do português europeu: pro ou variável? In: XXVI Encontro Nacional da Associação Portuguesa de Linguística. Textos Seleccionados 2010. pp. 197-207.

Costa, J., Lobo, M., Silva, C., 2009. Null objects and early pragmatics in the acquisition of European Portuguese. Probus 21 (2), $143-162$.

Duarte, I., Matos, G., 2000. Romance Clitics and the Minimalist Program. In: Costa, J. (Ed.), Portuguese Syntax. New Comparative Studies. Oxford University Press, Oxford, pp. 116-142.

Duarte, I., Matos, G., Faria, I., 1995. Specificity of European Portuguese Clitics in Romance. In: Hub Faria, I., Freitas, M.J. (Eds.), Studies on the Acquisition of Portuguese. APL/Colibri, Lisboa, pp. 129-154.

Duarte, I., Matos, G., Gonçalves, A., 2005. Pronominal clitics in European and Brazilian Portuguese. Journal of portuguese linguistic 4 (2) $113-141$.

Fiéis, A., 2001. Interpolação em Português Medieval como Adjunção a XP. In: Actas do XVI Encontro Nacional da Associação Portuguesa de Linguística. Colibri/APL, Lisboa, pp. 197-211.

Fiéis, A., Madeira, A., 2012. Predicados de controlo na diacronia do português. In: Costa, A., Flores, C., Alexandre, N. (orgs.), Textos Selecionados. XXVII Encontro Nacional da Associação Portuguesa de Linguística. APL, Lisboa, pp. 271-284.

Flores, C., Barbosa, P., 2012. When reduced input leads to delayed acquisition: a study on the acquisition of clitic placement by Portuguese heritage speakers. Int. J. Bilingualism FirstOnline Article. http://hdl.handle.net/1822/23580.

Frota, S., Vigário, M., 1996. On weight effects in European Portuguese. In: Paper presented at Glow Workshop on Weight Effects, Athens.

Fujino, H., Sano, T., 2002. Aspects of the null object phenomenon in child Spanish. In: Pérez-Leroux, A.T., Muñoz Liceras, J. (Eds.), The Acquisition of Spanish Morphosyntax. Kluwer, Dordrecht, pp. 67-88.

Galves, C., 2003. Sintaxe e estilo nos sermões do Padre Antonio Vieira. In: Alkmin, T., Albano, E., Hadler, M.I., Possenti, S. (Eds.), Saudades da Língua. Companhia das Letras, São Paulo, pp. 245-260.

Galves, C., Britto, H., Paixão de Sousa, M.C., 2005a. The change in clitic placement from Classical Portuguese to Modern European Portuguese: results from the Tycho Brahe Corpus. J. Portuguese Linguist. 4 (1), 39-67.

Galves, C., Torres Moraes, M.A., Ribeiro, I., 2005b. Pronominal Clitics in European and Brazilian Portuguese. J. Portuguese Linguist. 4 (2), 143-177.

Grüter, T., 2006. Object clitics and null objects in the acquisition of French. PhD diss., McGill Univ. Montreal.

Guasti, M.T., 1993/94. Verb syntax in Italian child grammar: finite and nonfinite verbs. Lang. Acquis. 3 (1), 1-40.

Hamann, C., Rizzi, L., Frauenfelder, U.H., 1996. On the acquisition of subject and object clitics in French. In: Clahsen, H. (Ed.), Generative Perspectives on Language Acquisition. John Benjamins, Amsterdam, pp. 309-334.

Ilic, T., Ud Deen, K., 2004. Object raising and cliticization in Serbo-Croatian child language. In: van Kampen, J., Baauw, S. (Eds.), The Proceedings of GALA 2003. LOT, Utrecht, Netherlands, pp. 235-243.

Jakubowicz, C., 2004. Is Movement Costly? The Grammar and the Processor. In: Language Acquisition. Paper presented at JEL'2004, Nantes, France, 5-7 May.

Jakubowicz, C., Nash, L., Rigaut, C., Gérard, C.-L., 1998. Determiners and Clitic Pronouns in French-Speaking Children with SLI. Lang. Acquis. 7 (2), 113-160.

Lobo, M., 2003. Aspectos da Sintaxe das Orações Subordinadas Adverbiais do Português. PhD diss., Univ. Nova de Lisboa.

Madeira, A., 1992. On Clitic Placement in European Portuguese. In: van de Koot, H. (Ed.), UCL Working Papers in Linguistics, vol. 4. Univ. College, Londres.

Marinis, T., 2000. The acquisition of clitic objects in Modern Greek: Single clitics, clitic doubling, clitic left dislocation. In: ZAS Papers in Linguistics 15. ZAS, Berlin, pp. 259-281.

Martins, A.M., 1994. Clíticos na História do Português. PhD diss., Univ. Lisboa.

Martins, A.M., 2011. Clíticos na história do português à luz do teatro vicentino. Estudos de Lingüística Galega 3, 83-109. 
Miller, K., Schmitt, C., 2010. Effects of variable input in the acquisition of plural in two dialects of Spanish. Lingua 120 (5), 1178-1193.

Neokleous, T., in press. Clitic (Mis)Placement in Early Grammars: Evidence from Cypriot Greek. In: Advances in Language Acquisition. Cambridge Scholars Publishing, Newcastle-Upon-Tyne.

Ogando, V., 1980. A colocación do pronome átono en relación co verbo no galego-portugués medieval. Verba 7, $251-282$.

Pagotto, E.G., 1996. Clíticos, Mudança e Seleção Natural. In: Roberts, I., Kato, M. (orgs.), Português Brasileiro (uma viagem diacrônica). Unicamp, Campinas, pp. 185-206.

Paixão de Sousa, M.C., 2004. Língua Barroca: Sintaxe e História do Português de 1600. Instituto de Estudos da Linguagem, Universidade Estadual de Campinas, Campinas, S.P.PhD diss.

Petinou, K., Terzi, A., 2002. Clitic misplacement among normally developing children and children with specific language impairment and the status of Infl heads. Lang. Acquis. 10 (1), 1-28.

Reglero, L., Ticio, E., 2003. The acquisition of clitics in child Spanish. In: Montrul, S., Ordoñez, F. (Eds.), Linguistic Theory and Language Development in Hispanic Languages. Cascadilla Press, Sommerville, MA, pp. 297-316.

Rouveret, A., 1992. Clitic placement, Focus and the Wackernagel Position in European Portuguese. ms. Univ. Paris 8.

Santos, Nascimento dos, M.F., 2002. Os Pronomes Pessoais Átonos no Português Europeu. Descrição de Problemas que Ocorrem no $3^{\circ}$ ciclo e Proposta de Actividades Didácticas. MA diss., FLUL.

Schaeffer, J., 2000. The Acquisition of Direct Object Scrambling and Clitic Placement: Syntax and Pragmatics. Benjamins, Amsterdam.

Silva, C., 2008. Assimetrias na aquisição de clíticos diferenciados em português europeu. Dissertação de mestrado, Faculdade de Ciências Sociais e Humanas, Universidade Nova de Lisboa.

Soares, C., 2006. La syntaxe de la périphérie gauche et son acquisition en Portugais Européen. PhD diss. Paris, Univ. Paris 8.

Tsakali, V., Wexler, K., 2003. Why children omit clitics in some languages but not in others: new evidence from Greek. In: van Kampen, J., Baauw, S. (Eds.), Proceedings of GALA 2003. LOT, Utrecht, pp. 493-504.

Wexler, K., Gavarrò, A., Torrens, V., 2004. Feature checking and object clitic omission in child Catalan and Spanish. In: Bok-Bennema, R., Hollebrandse, B., Kampers-Manhe, B., Sleeman, P. (Eds.), Romance Languages and Linguistic Theory 2002. John Benjamins, Amsterdam, pp. 253-268. 